\title{
Retórica e dialética no ensino jurídico em uma democracia
}

\section{Juridical teaching: rhetoric and dialect in democracy}

\author{
Natércia Sampaio Siqueira* \\ Marcelo Sampaio Siqueira*
}

\section{Resumo}

O presente artigo trata da metodologia adequada ao Direito em uma democracia. Em um primeiro momento, analisa-se a inadequação da indução e dedução como métodos jurídicos. Posteriormente, advoga-se que a dialética, a consubstanciar uma relação de implicação entre fato e norma, é a metodologia propícia à prática jurídica de uma democracia. Mas a dialética não deve ser percebida como exercício intimista; antes, deve ser realizada mediante prática argumentativa coerente e inclusiva. Aplicando as referidas constatações à sala de aula, a conclusão é que o ensino jurídico deve apropriar-se da incerteza imanente ao conhecimento, adotando a dialética como método adequado ao Direito, mediante o conhecimento totalizante do fato e o questionamento axiológico da norma. E mais: o raciocínio dialético deve ser praticado pela retórica, formando-se o aluno na arte da compreensão, coerência e persuasão.

Palavras-chave: Ensino jurídico. Dialética. Retórica. Diálogo.

\section{Abstract}

This paper researches the law's methodology in the democracy. In first time, is analyzed the induction and deduction as law's methodology, to show its inability

Possui graduação pela Faculdade de Direito da Universidade do Ceará, mestrado em Direito Tributário pela pela Faculdade de Direito da Universidade Federal de Minas Gerais e Doutorado em Direito Constitucional pela Universidade de Fortaleza. Atualmente, é professora da graduação e do programa de Mestrado e Doutorado em Direito Constitucional na Universidade de Fortaleza e Procuradora fiscal do Município de Fortaleza. Fortaleza - CE - Brasil. Email: naterciasiqueira@ yahoo.com.br

* Possui graduação pela Faculdade de Direito da Universidade Federal do Ceará, mestrado em Direito Público pela Faculdade de Direito da Universidade Federal do Ceará e Doutorado em Direito Constitucional pela Universidade de Fortaleza. Fortaleza - CE - Brasil. 
to juridical practice. In second moment, this article brings the dialect to law, that consubstantiate a relationship between fact and norm different from syllogism. But the dialect mustn't understood like intimate exercise, but like argumentative practice coherent and inclusive. Appling these issues to juridical teaching, the conclusion is that: teachers and students must appropriate from the uncertainness inherent to knowledge, adopting the dialect like law's methodology, through full comprehension of fact and norm's philosophic critique. More: the dialect must be practice by rhetoric, shaping the student in art of comprehension, coherence and persuasion

Keywords: Juridical teachng.Dialect. Rhetoric. Dialogue.

\section{Introdução}

A proliferação dos cursos de Direito, assim como das carreiras jurídicas, tem chamado atenção para o fraco desempenho dos alunos nas provas da Ordem dos Advogados do Brasil (OAB) e nos concursos públicos, como se o problema da formação jurídica a isso se resumisse. Mas outras questões assomam.

Paradoxalmente, a preocupação com a aprovação na $O A B$ e em concursos públicos, concomitante ao discurso dogmático da "fundamentalização" e "judicialização" do Direito, vem contribuindo para a manutenção do equívoco metodológico que grande prejuízo traz à formação jurídica: o silogismo, que tem adquirido caráter jurisprudencial, sendo praticado sem ânimo crítico nem esforço de integração.

Isso significa uma falha estrutural na construção de uma prática que se pretende adequada às democracias contemporâneas. Partindo dessa problemática, a proposta central prende-se à dialética, realizada no esforço argumentativo como metodologia adequada à formação dos juristas em uma sociedade democrática.

Para tanto, empregando pesquisa bibliográfica e com esteio nas doutrinas nacional e estrangeira, o presente artigo desenvolve-se através do seguinte roteiro: em um primeiro momento, analisa-se a 
falibilidade do silogismo, praticado mediante as técnicas da indução e dedução como método adequado ao Direito, o qual deve ser praticado pelo método dialético, a consubstanciar uma relação de implicação (em vez de identidade) entre fato e norma.

Posteriormente, passa-se à análise da argumentação como dinâmica metodológica alternativa para a construção de um Direito democrático, com ênfase no conhecimento do auditório,.

Por último, aborda-se a formação do jurista em sala de aula mediante a aplicação do método dialético, desenvolvido como prática argumentativa, exigindo-se a incursão por saberes afins ao Direito, como a Filosofia e ciências adjacentes - Sociologia, Economia, Antropologia, Psicologia e Medicina -, bem como o treinamento axiológico e epistemológico da compreensão e persuasão. Ao final, a conclusão é que o ensino jurídico deve empenhar-se em trabalhar as qualidades do compreender e convencer, dedicando-se à construção de uma prémentalidade de cidadania democrática, participativa e integrativa.

\section{Desacertos metodológicos}

O lluminismo abandona a explicação da verdade em Deus para abraçar a crença na racionalidade humana: o homem, munido de sua racionalidade, seria capaz de alcançar a verdade dos fenômenos, dos eventos e dos bens.

A racionalidade, por sua vez, manifestar-se-ia, por excelência, no conhecimento científico, que, depurado de toda subjetividade, possibilitaria alcançar a verdade do objeto analisado através dos movimentos de indução e dedução.

O objeto que se pretendesse descoberto na sua realidade deveria ser subordinado ao conhecimento científico, caracterizado pela objetividade e rigorosa análise - tendência epistemológica que alcançou seu ápice no Positivismo de Augusto Comte. A prática de se conhecer o objeto pela indução e dedução, longe de questionamentos causais de ordem metafísica, espalha-se pelos diversos ramos científicos, 
sob a crença - por que não adjetivar de "mística" - na objetividade do conhecimento.

Dessa forma, tanto os fenômenos da natureza, mais propícios às técnicas silogísticas, como os fenômenos culturais passariam a sujeitarse à dinâmica causa-efeito, com o propósito de descoberta da verdade, sem a interferência do sujeito cognoscente (ALVES-MAZZOTTI; GEWANDSZNAJDER, 2002).

Daí não se estranhar que o Direito, mesmo classificando-se entre as ciências sociais, tenha se prestado à analogia com as ciências naturais. O fenômeno jurídico foi equiparado aos eventos da física e da química. A sua dinâmica foi enclausurada nos movimentos da indução e da dedução, sob a crença da neutralidade dos operadores do Direito, os quais desvendariam a norma adequada ao caso concreto.

Becker (1998, p. 308), ao trabalhar a dinâmica imputacional tributária, expõe com perfeição a analogia entre eventos naturais e fenômeno jurídico:

A juridicidade tem grande analogia com a energia eletromagnética e a incidência da regra jurídica projeta-se e atua com autonomatismo, instantaneidade e efeitos muitos semelhantes a uma descarga eletromagnética.

Um instrumento (regra jurídica válida) carregado de energia eletromagnética (juridicidade). Este instrumento permanece suspenso sobre o mundo dos fatos físicos, biológicos e psíquicos [...]

Ora, com o acontecer dos fatos, vão se realizando (existindo no presente e no pretérito), um a um, os elementos previstos na composição da hipótese de incidência, quando todos os elementos se realizaram (existem no presente e no pretérito), a hipótese de incidência realizou-se e, então, automaticamente (imediata, instantânea e infalivelmente), aquele instrumento entra em dinâmica e projeta uma descarga (incidência) de energia eletromagnética (juridicidade) sobre a hipótese de incidência realizada.

Recebendo esta carga de energia (de juridicidade), a hipótese de incidência fica carregada de energia eletromagnética 
(juridiciza-se) em estado dinâmico, cujo efeito é a irradiação (pela hipótese de incidência já juridicizada) da eficácia jurídica: a relação jurídica e seu conteúdo jurídico de direito e correlativo dever, de pretensão e correlativa obrigação, de coação e correlativa sujeição.

Observa-se, em um primeiro momento, que o texto, ao realizar a analogia entre o fenômeno jurídico e o físico, experiencia o Direito como necessidade governada pela identidade das causas com os efeitos - a ocorrência, no mundo fenomenológico, do fato descrito em lei seria suficiente para o surgimento da relação jurídica nela prevista. Nada diferiria do que ocorre nas ciências naturais: a água evapora a cem graus, a junção de um átomo de hidrogênio com dois de oxigênio resulta na molécula de água e uma maçã cai ao desprender-se do galho que a segurava (CÓSSIO, 2007).

No Direito, na Física e na Química, a ocorrência de um fato previsto nas leis gera, inevitável e imediatamente, a consequência nelas descritas. Nesse contexto, a atividade do jurista não difere substancialmente da atividade do físico e do químico: reconhecer as normas que regem os eventos, analisar a correspondência entre os fatos reais e as hipóteses normativas, e descrever as inevitáveis consequências do "fato-causa" realizado fenomenologicamente.

Importa ainda frisar que o silogismo legal, justificado no cientificismo ao qual está subordinado o Direito, ao repudiar considerações metafísicas, revelou-se a epistemologia jurídica adequada à mentalidade liberal burguesa. A vivência do liberalismo no final do século XVIII e durante o século XIX, em reação ao absolutismo monárquico, apresentou como relevante aspiração a sujeição de todos à vontade geral, manifesta na letra da lei. Como vantagem adicional, o silogismo legal dotava o Direito de segurança e estabilidade, afastando-o do arbítrio dos julgadores. Ou seja, reter o Direito à letra da lei, sob a dinâmica da indução e da dedução, não apenas reforçava a convicção da sujeição à vontade geral como afastava a prática jurídica do arbítrio judicial, mediante metodologia que Ihe conferia aparente exatidão, alimentando a crença 
de o Direito não se encontrar à mercê dos homens, e sim ao abrigo de instituições relativamente impessoais (PERELMAN, 1997).

Ocorre que, mesmo entre os principais teóricos do liberalismo, nascia a desconfiança quanto à possibilidade do conhecimento absolutamente objetivo. Kant, tendo despertado do sono dogmático mediante as considerações de Hume, tece a crítica da razão pura:

Ceticismo e dogmatismo são as duas terminais da metafísica. O primeiro se assemelha ao caos, à anarquia da ordem social; o segundo ao despotismo. O instrumento da superação dessas correntes estéreis é o criticismo, com que Kant pretende evitar aquelas consequências que o unilateralismo traz. O conhecimento não poderá desprezar a razão como fonte de representações a priori, nem os sentidos como lugar da ocorrência do objeto. $O$ racional e o sensível devem estar, pois, presentes em todo conhecimento, para evitar o vôo das idéias no 'espaço vazio do entendimento puro', como ocorreu com Platão. (SALGADO, 1995, p. 84)

Mas se a crítica de Kant é dirigida ao conhecimento como um todo em relação à ciência jurídica, a complexidade social e econômica gerou uma realidade que não se moldava à disciplina por um Direito causal, caracterizado pela imputação. A utilização da lógica dedutiva formal falhava, em não raros casos, na regulação razoável de situações cotidianas, expondo a fragilidade e a ineficiência do Direito.

Para ilustrar, são pitorescos os exemplos fornecidos por Perelman (1997): a norma proibitiva da entrada de cachorros em ambientes públicos, como estações ferroviárias, seria aplicável a ursos domesticados? A vedação do trânsito de veículos automotores subsistiria em casos de emergência, como o transporte efetuado por ambulância? O agravamento do furto à noite aplicar-se-ia nas situações de escuridão e repouso das vítimas, mesmo que, tecnicamente, não configurasse o período noturno? Para a resolução razoável dos referidos casos, seria necessária uma consideração acerca da finalidade da norma, que começou a ser introduzida no cenário jurídico europeu ainda no século XIX. 
A consideração à finalidade do Direito, o que permitia estender a consequência jurídica de uma norma geral a um fato por ela não tipificado, ou obstar a sua aplicação a fatos por ela tipificados, é uma primeira ruptura com as técnicas indutiva e dedutiva, caracterizadas pela identidade entre fato real e fato normativo. Mas o desconforto de tratar o Direito como fenômeno da natureza aumentou com o paradigma da supremacia da Constituição. Assim, a "constituição se coloca num plano superior às demais normas porque regula o procedimento de formação, tanto no aspecto formal, como no material" (DINIZ, 2002, p. 104).

A subordinação da lei à Constituição, aliada ao fato de várias Constituições terem positivado os princípios do Direito natural, tais como igualdade, liberdade e dignidade, revelou que a subsunção do fato à norma não mais se mostrava suficiente ao fenômeno jurídico (FIGUEROA, 1998). Face às peculiaridades do caso concreto, se a lei mostra-se injusta ou desigual, ela deve ser adaptada ou mesmo afastada.

Veja-se bem: considerações acerca da finalidade e da "justiça" da norma geral a serem aplicadas ao caso concreto afastam o Direito do raciocínio subsuntivo, em que a norma, na sua literalidade, é aplicada apenas ao fato que se identifique ao regulado por ela. O movimento de indução do caso concreto à norma geral e de dedução desta àquele é substituído por uma dinâmica bem mais complexa, na qual a norma é contrastada à Constituição e adaptada às peculiaridades do caso concreto, em um movimento dialético de contínuo acréscimo de conteúdo, sob análise crítica do Direito.

\section{Carlos Cóssio: do fato normativo ao fato social, do Positivismo à dialética}

No esforço de diferenciar o Direito de outras ciências, o argentino Carlos Cóssio, filósofo do Direito, afirmou que o objeto do Direito é a conduta humana em interferência intersubjetiva. 
Tal afirmação contrastou-se com a teoria de Hans Kelsen, à época dominante. Para Kelsen, o Direito seria um sistema hierárquico e coercitivo de normas, o objeto da ciência jurídica seria a norma jurídica e o respectivo método refletiria a ideia de que o Direito regula a própria criação, realizando-se por uma cadeia de imputação normativa. Com isso, afastar-se-ia o sincretismo metodológico então dominante na ciência jurídica.

Ocorre que o debate quanto ao real objeto do Direito não é meramente formal. Pelo contrário, a afirmação de que o objeto da ciência jurídica é norma ou conduta implica diferentes formas de compreensão e vivência do Direito. Dizer que o objeto do Direito é conduta não significa afirmar que o Direito é a realização do fato descrito na norma, o que seria mera tautologia à afirmação de que o Direito é a norma. A afirmação feita por Carlos Cóssio busca realçar a relação de implicação entre o fato e a norma, afastando-se da relação de identidade entre o fato real e o normativo.

Traçando o diferente papel que o fato assume para a teoria pura de Hans Kelsen, normativa, e a de Carlos Cóssio, egológica, explica Vasconcelos (2003, p.128-129):

[...] Em que residirá, afinal, a diferença entre a conduta humana como objeto da teoria pura e a mesma conduta humana como objeto da teoria egológica?

A diferença parece estar aqui: enquanto a conduta da teoria egológica é conteúdo material, devendo ser apreciada sociologicamente, a conduta da teoria normativista constitui conteúdo meramente formal, somente apreensível através do raciocínio abstrato, como puro nexo do dever-ser lógico. Não nos esqueçamos da advertência de Legaz Y Lacambra, segundo a qual, o direito-norma-jurídica, de inspiração Kelseniana, 'é realidade mental, construída ex novo unicamente pela força do pensador' [...]

O fato concreto a ser regulado pelo Direito não seria mais analisado pela relação de perfeita identidade com a hipótese descrita na norma legal; ele passa a ter significado social próprio, influindo no 
conteúdo da norma. A substituição da relação de identidade pela relação de complementaridade e implicação entre fato social e norma, levou Cóssio (2007, p. 59-60) a tratar a dialética como método propício ao Direito, que é objeto cultural:

[...] Siempre hemos de toparnos com la exteriorización sensible de um sentido espiritual al que hay que llegar interpretando esse substrato externo. Pero la relación entre el substrato y el sentido no es recíproca com la misma significación, como cuando se recorre um mismo camiño de ida y de vuelta. El camiño aqui es diferente a la ida que a la vuelta porque comprendemos el substrato por su sentido y compreendemos el sentido em su substrato. Esto hace ver que se trata de uma relación gnoseológica de caráter dialético, em cuanto que um término remite al otro y vice versa, pero que se despliega em um movimento circular indefinido cuyo progreso lleva, alternativamente, a pasar outra vez por el término que ya se dejó atrás. Y el espíritu corta la dialética circular ínsita em este conocimiento, cuando cree poseer el debido ajuste entre la expresión y lo expressado. De ahí que lo conociemento de lo cultural puede enriquecerse indefinidamente com nuovos matices.

Pelo método dialético, há uma relação de acréscimo de significados entre o fato (substrato material) e a norma (sentido espiritual): o fato é compreendido pela norma, que é compreendida no fato, numa dinâmica que não se limita à relação de precisa identidade entre fato e norma. 0 Direito não se esgota no texto normativo a ser aplicado na sua exata literalidade sempre que verificada a existência de um fato idêntico ao por ele tipificado. O fato, como realidade própria, não apenas é entendido pelo texto normativo como influencia o seu conteúdo.

\section{Chaïm Perelman: da verdade à argumentação}

A relação de implicação entre fato e norma sob a dinâmica dialética, em substituição às práticas de indução e dedução caracterizadas pela identidade entre o fato real e norma geral, chama atenção para a 
presença ativa e criativa do operador do Direito na resolução do caso concreto.

Infelizmente, o estudo do Direito no Brasil, em muitos cursos de graduação, mantém-se míope quanto ao papel criativo do operador do Direito, limitando o ensino à sala de aula, a códigos e súmulas jurisprudenciais, com foco no resultado da prova da OAB e em concursos, sem perspectiva crítica quanto ao significado e à prática do Direito (MORAIS; SANTOS, 2007). Ainda que sob o discurso da juridicidade em substituição ao da legalidade, muitos dos alunos e professores fixam-se nos textos legais e jurisprudenciais, percebidos como dados objetivos "baixados" por sites de buscas, sem efetiva vivência da dialética e, o que é mais grave, praticando a indução e dedução sob a nomenclatura do método dialético.

Especialmente preocupado com os equívocos metodológicos referentes ao Direito, em meados do século XX, Perelman (1999) já afirmava que o Direito não se realiza pela lógica formal da demonstração, mas pela lógica da argumentação, através de provas dialéticas, com o propósito de convencimento do auditório. Antes da verdade, que a todos submete, a prática jurídica se realizaria pelo esforço de persuasão sobre o preferível, integrando seus partícipes na construção do Direito.

É rica a imagem que Perelman (1999) oferece: o Direito, antes de realizar-se por demonstração formal de subsunção do fato à norma e de aplicação desta àquele, realiza-se pela argumentação razoável, com busca à aceitação do auditório. Nessa prática, o Direito ganha em legitimidade e democracia, pois, antes do império da lógica indutiva/ dedutiva, passa-se à aceitabilidade dos argumentos. Para uma teoria ser considerada válida, não é suficiente que seja lógica, sistemática e bem formulada. Ela precisa ser aceita (DEMO, 2000), compreendida e legitimada pelo auditório, pelas partes a quem se dirige, pela sociedade como um todo. A retórica enreda-se pelo esforço de persuasão e aceitação, demandando conexão com a realidade, com os sentimentos e com as perspectivas sociais então vigentes. 


\section{Sala de aula: a formação do jurista}

As premissas metodológicas expostas, próprias ao Direito contemporâneo, devem ser vivenciadas pelos operadores do Direito em seu cotidiano; mais precisamente, devem formar a pré-mentalidade dos juristas. Dessa forma, antes de fechar-se em livros, palestras e congressos, a dialética e a argumentação devem ser atávicas a quem trabalha com o Direito. No entanto, isso só se mostra atingível mediante a adaptação do ensino universitário à metodologia propícia ao Direito.

\subsection{Conhecendo o conhecimento}

O primeiro passo consiste em libertar o ensino jurídico da crença positiva na objetividade do conhecimento e na neutralidade do observador, que são fortes argumentos a sustentar a relação de identidade do fato à norma (indução) e da norma ao fato (dedução). Para superar o raciocínio subsuntivo, deve-se reconhecer a impossibilidade da descoberta do objeto na sua realidade: "o conhecimento não é um espelho das coisas ou do mundo externo. Todas as percepções são, ao mesmo tempo, traduções e reconstruções cerebrais com base em estímulos ou sinais captados e codificados pelos sentidos" (MORIN, 2007, p. 20).

Morin (2007) prossegue atacando o mito da neutralidade do observador, manifesto na possibilidade de conhecimento do objeto pela inteligência, despida de qualquer afetividade. Consciente do "mito" da objetividade epistemológica, o ensino do Direito está pronto para aventurar-se pelo método propício à prática jurídica: a dialética, realizada pela dinâmica de implicação entre fato e norma.

O reconhecimento da "imprecisão" como dado imanente ao conhecimento libera o ensino jurídico do propósito de alcançar o Direito "posto" e "existente" mediante a depuração de qualquer subjetivismo por parte do intérprete. Os professores e alunos, libertos da ficção da objetividade, sentem-se à vontade para romper com a analogia entre metodologia jurídica e ciências exatas, tateando novos caminhos, bem mais adequados ao fenômeno jurídico. 


\subsection{O conhecimento totalizante do fato}

As considerações, entretanto, não param aqui. É preciso observar que o processo dialético entre o fato e a norma areja o conhecimento jurídico, que se liberta da clausura literal. Na sala de aula, não se deve mais limitar-se ao texto das leis ou da jurisprudência sem perspectiva crítica do Direito. É necessário abrir-se para a realidade social, pois o fato, como elemento autônomo a influir no conteúdo da norma, precisa ser apreendido no contexto em que foi produzido e nas várias dimensões em que se mostra cognoscível - econômica, psicológica, antropológica, sociológica, física, química etc.

Ou seja, mais do que o conhecimento "especializado" da norma, mediante o qual o fato seria apreensível numa relação de identidade, o ensino jurídico deve aventurar-se pela multiplicidade do conhecimento, com enfoque no contexto, no global, no multidimensional e no complexo (MORIN, 2007). O fato deve ser observado e compreendido na realidade em que produzido, em conexão com os aspectos psicológicos dos seus agentes e destinatários, e em consideração aos seus efeitos, mediante análise complexa a conectar todos esses aspectos.

Antes de contrastar o fato à norma, conhecendo-o pelos textos normativos, ele deve ser apreendido no seu "todo" social. É fundamental que se forme e se prepare a mentalidade do aluno para reconhecer a autonomia do fato perante a norma, com conhecimentos técnicos adequados para conhecer este na sua integralidade.

Nos Estados Unidos, a Universidade de Chicago desenvolveu uma metodologia denominada de Law and Economics, na qual as leis e as relações econômicas são analisadas com o intuito de adaptá-las e aplicá-las ao Direito, tornando-o eficiente. Mas não é só. Questões ligadas à bioética, como aborto, tratamento com células-tronco e eutanásia, demandam uma incursão na ética médica, a fim de elucidar a natureza das oposições que comumente lhes são levantadas: seriam fruto de concepções religiosas, filosóficas ou morais repletas de preconceitos e subjetivismos, ou encontrariam respaldo na compreensão do que seja a vida para a Medicina? A análise de dados médicos sobre aborto e 
eutanásia permite apreender o impacto dessas práticas na saúde pública e possibilita a catalogação, de forma racional e científica, dos seus efeitos negativos e positivos nas políticas públicas e no desenvolvimento social.

Compreender o fato pela perspectiva da sociedade é fundamental para a construção de uma prática jurídica aceitável. Se o sentimento social resguarda preconceitos inadmissíveis, também revela a superação de preconceitos igualmente inaceitáveis na vivência da democracia, mas ainda incorporados no texto legal. A superação de antigos sentimentos discriminatórios amplia a liberdade humana, e a sua apreensão pelo jurista possibilita a adaptação do Direito à realidade.

A compreensão do fato em suas várias dimensões imprime eficiência ao Direito, além de dotá-lo de racionalidade e razoabilidade, por afastá-lo de preconceitos e subjetivismos acerca do certo e do errado. Além disso, possibilita a sua adaptabilidade à realidade, a sua aceitação e legitimidade - elementos imprescindíveis à vivência de uma real democracia.

\subsection{Incursão pela Filosofia}

Por outro lado, a norma jurídica não se limita à lei, alcançando a Constituição, que se encontra em posição de supremacia em relação à lei. A Constituição, por sua vez, em vários Estados ocidentais, adquiriu caráter normativo e adotou princípios do Direito natural: igualdade, justiça, liberdade, solidariedade etc. Tal alteração de perspectiva - positivação constitucional do Direito natural - tornou óbvio que as grandes questões jurídicas não prescindem da Filosofia e de indagações quanto ao correto e ao justo (ENCARNAÇÃO, 1995).

É bem verdade que até o Positivismo demandou explicações de ordem filosófica e metodológica. Entretanto, ele permitiu a segmentação entre Direito e Filosofia, criando a ilusão de que as questões jurídicas se resolveriam pela lei, sem indagações sobre o correto e o justo. Mas a normatização e constitucionalização dos direitos fundamentais trouxeram a Filosofia de volta ao Direito, propiciando a construção de 
uma prática jurídica que comumente se questiona acerca da justiça da aplicação do texto normativo ao caso concreto.

Justiça é um conceito complexo, que trabalha com os critérios de distribuição de bens, sejam eles riqueza, prerrogativas, prestígio social, poder, funções, cargos, liberdades ou direitos. Não por menos, as questões de justiça estendem-se desde a esfera política até as esferas econômica e privada, consubstanciando as mais elementares indagações sobre as instituições sociais basilares de uma democracia: existem princípios prévios de justiça que sejam condicionantes do processo político democrático ou ele possui plena disponibilidade sobre o conteúdo de suas decisões? A "fundamentalização" e "judicialização" do Direito, ao reconhecerem uma crescente gama de princípios e direitos prévios e condicionantes do processo político democrático, são compatíveis com a democracia? O reconhecimento da igualdade e liberdade como princípios elementares da justiça em uma democracia aplica-se à esfera privada ou limita-se ao espaço público? O paternalismo e corporativismo estatal são compatíveis com os ideais democráticos? Qual o limite de políticas sociais: o mercado apresenta elementos axiológicos que devem ser observados como condicionantes à redistribuição de renda e patrimônio? É justo que uma pessoa possua maior riqueza, recursos, poder e prestígio do que outras em razão das suas aptidões e talentos naturais? As características referentes ao sexo, idade, raça, família, assim como as debilidades físicas e mentais, devem ser levadas em consideração por uma política pública de distribuição de riqueza e alocação de direitos?

Nesses debates, que se revelam a última instância de questões basilares e cotidianas nas relações públicas e privadas de uma democracia, enfrentam-se várias vertentes da filosofia política, econômica e antropológica da atualidade: liberalismo econômico e político, comunitarismo, republicanismo e capacidades, apenas para citar as de maior notoriedade, com esteio nos mais importantes pensadores ocidentais, como John Rawls, Ronald Dworkin, Habermas, Ian Shaphiro, Martha Nussbaun, Amarthya Sen, Hannah Arendt, Isaiah Berlin, Friedrich Hayek, Freud, Nietzsche, Stuart Mill, Rousseau, Locke, 
Aristóteles, Platão... A lista estende-se por pensadores de diferentes períodos históricos, mas que colaboraram e colaboram na construção de um pensar eminentemente ocidental, o qual deve ser apreendido e compreendido pelos "trabalhadores" do Direito, de forma a se dotar o debate sobre as grandes questões jurídicas de racionalidade, longe de preconceitos e subjetivismos, que sempre encontram guarida na vaguidade dos princípios constitucionais.

Enfim, deve o ensino jurídico estender-se pelas grandes questões da Filosofia, presentes no desenrolar da história. O que há: uma interpenetração entre fato social, textos normativos e conceitos filosóficos, que se mesclam em uma relação dialética em busca da resolução adequada aos casos concretos. No atual panorama do conhecimento jurídico, o "fato social" é compreendido pelos "elementos normativos", os quais são compreendidos no "fato", numa contínua alteração e acréscimo de conteúdo. As singularidades fáticas, quando relevantes, demandam a exploração de novos significados normativos, cuja aplicação encontra por medida a justiça. O ambiente jurídico, por consequência, deve ser informado pela interdisciplinariedade, o que significa que ao ensino do Direito não se faz suficiente o estudo dos códigos, das leis, dos regulamentos, das resoluções e da jurisprudência, ou seja, dos textos normativos. Antes, deve-se excursionar pelos conhecimentos científicos adjacentes (Economia, Sociologia, Medicina, Física, Química, Psicologia), que permitem a apreensão multidimensional dos fatos, assim como pela Filosofia, que integra, informa, condiciona e inspira o conteúdo das normas jurídicas.

4.4 O enfrentamento da incerteza no conhecimento jurídico: a prática da argumentação

Importa ainda perceber que a empreitada intelectual a ser seguida na sala de aula afasta-se, e muito, da certeza que se pretendia com a aplicação do silogismo ao Direito, no qual os alunos eram treinados para identificar os fatos aos textos normativos e aplicá-los no limite do seu significado semântico. A ausência da análise multidisciplinar do fato 
e de considerações críticas à norma permitia ao operador uma relativa segurança quanto à resolução do caso concreto, o que não mais é possível com a dialética.

O método dialético, com a consequente liberação do fato de uma relação de identidade com a norma, assim como a análise axiológica do Direito positivo, são fatores que tornam evidente o caráter de incerteza do conhecimento jurídico. Antes camuflado, deve ser percebido e apreendido, para que possibilite, ao Direito, novas oportunidades e perspectivas (MORIN, 2007). O raciocínio subsuntivo, caracterizado pela indução do fato à norma e pela dedução da norma ao fato, enclausurava o Direito no texto normativo, sendo aplicado sem consideração à justiça e à aceitabilidade social. Não importavam as consequências do resultado; sempre que ocorrido fato idêntico ao descrito na norma, tinha-se que aplicá-la. Mas, ao utilizar-se do método dialético, a aplicação do Direito recepciona a análise axiológica da norma e multidimensional do fato, permitindo a adaptabilidade do Direito ao meio social. É, sem dúvidas, uma relevante oportunidade, não obstante o risco da incerteza.

Mas a compreensão de que a melhor opção epistemológica é a conscientização sobre a incerteza inerente ao conhecimento, possibilitando ao Direito as várias oportunidades dela decorrentes, não significa o término do esforço para precaver a prática jurídica do subjetivismo exacerbado. É fundamental evitar que o Direito se transforme em um caleidoscópio de opiniões discordantes e sem fundamento, com respaldo única e exclusivamente na voluntariedade de quem o pratica.

Para tanto, a prática da argumentação razoável, com enfoque na aceitabilidade do auditório, é fundamental. O professor, antes de se limitar à demonstração silogística, deve desenvolver seu raciocínio pela lógica da argumentação, com esforço em alcançar a aceitação dos seus alunos. De igual sorte, os alunos devem ser estimulados a praticarem o Direito mediante argumentos razoáveis, capazes de obter a adesão do auditório. A sala de aula passa a funcionar como o primeiro laboratório prático da retórica jurídica, com enfoque na adesão. O esforço intelectual 
não se limita à demonstração da justeza e precisão do silogismo, e muito menos se caracteriza pelo voluntarismo da autoridade; antes, deve movimentar-se na direção do convencimento e da aceitação, refletindo uma prática intelectual democrática, estruturada nos moldes do diálogo.

Para convencer, um elemento não apenas epistemológico e retórico, mas axiológico, é a coerência dos argumentos. Dworkin (2011), em sua última obra, Justice for Hedgehogs, após ater-se no dilema entre o cético exterior e interior, foca-se na coerência ou integridade do argumento, que qualifica uma interpretação como responsável. Ele transforma a coerência em elemento integrante do princípio moral da autenticidade: cada pessoa deve fazer da sua vida uma narrativa coerente ao que efetivamente valoriza. A responsabilidade e integridade são alçadas ao status de princípios ético e moral que devem reger os assuntos de fórum íntimo do indivíduo, as relações privadas e públicas, assim como o debate hermenêutico sobre qual seria a correta interpretação ou opinião.

A seriedade do argumento passa pela construção coerente de uma tese ou justificativa, mas o convencimento pressupõe a compreensão. Não se pode convencer sem compreender, o que reivindica a apreensão multidimensional e totalizante do fato. Um dos grandes desafios da sala de aula passa a ser, então, o de treinar o diálogo, realizado pela dinâmica do compreender e convencer. O locutor deve se despir da pretensão de verdade universal, conscientizando-se da sua função de "convencimento" dos interlocutores, o que pressupõe o esforço da compreensão. Essa dinâmica, que em maior ou menor intensidade se faz presente na atividade dos advogados, quando se esmeram no convencimento do juiz, deve, igualmente, formar a mentalidade dos julgadores, que ao proferirem decisões devem buscar a aceitabilidade do meio.

\subsection{Formação do espírito democrático}

Tudo o que foi tratado anteriormente implica que a argumentação não prescinde do conhecimento totalizante e complexo, cujos tentáculos 
se estendem por entre os mais diversos ramos do saber. Mas não se pode deixar de frisar: a argumentação é prática tanto ou mais importante, não apenas por exercitar a pluralidade do conhecimento ao passo em que impede o Direito de se degenerar em subjetivismo, mas porque cria uma dinâmica jurídica participativa, manifestada no binômio compreender/ convencer, próprio da democracia.

A argumentação insere o indivíduo em uma dinâmica ativa e criativa de interpretação. Nela, o operador do Direito não é observador neutro a descortinar a norma aplicável ao caso concreto. Ele participa, como agente dotado de inteligência e afeto, de uma dinâmica criativa do Direito, a consubstanciar uma "relação rica e complexa indivíduo/ sociedade, em que os indivíduos e a sociedade podem ajudar-se, desenvolver-se, regular-se e controlar-se mutuamente" (MORIN, 2007, p. 107).

O caráter democrático, nos moldes em que tratou Morin (2007), é inegável: como participante ativo da dinâmica jurídica, o operador do Direito integra um processo de criação, no qual se insere como pessoa responsável e engajada na comunidade. Quando demonstrada a precisão do silogismo, o Direito não mais se realiza pelo autoritarismo da lógica formal, pelo distanciamento - neutralidade - do intérprete e pela pacífica e irrestrita aceitação do auditório à solução do caso concreto. 0 Direito, com vistas à adesão e aceitação, implica inserção, participação e, consequentemente, responsabilidade.

Dessa forma, a aula, ao engajar aluno e professor em um processo ativo de retórica jurídica, deve trabalhar a consciência democrática dos alunos - sua condição de cidadão responsável e participativo. Até porque, como já está explícito, o Direito realizado pela metodologia da dialética e na forma da argumentação possibilita a atualização do fenômeno jurídico à realidade social.

Muitas das evoluções do Direito deram-se não no momento da legislação, mas por ocasião da resolução do caso concreto - atividade na qual se detém, preferencialmente, o ensino jurídico. O reconhecimento de direitos de minorias, como dos homossexuais, das mulheres e 
das companheiras, foi resultado do trabalho de juízes para, somente depois, serem albergados pelo Legislativo mediante a edição de leis. Fica patente a participação e a importância da atividade de resolução do caso concreto no processo de criação e evolução do Direito.

Consciente, portanto, de que a resolução do caso concreto é a etapa que integra a criação do Direito, avulta a necessidade de trabalhar o espírito democrático dos futuros operadores jurídicos que efetivamente estarão a participar da elaboração de normas a reger a sociedade. Esses operadores não foram eleitos pelo povo, não exercem mandato eletivo nem atuam mediante programa político. Nesse quesito, difere o papel do juiz e o do legislador. Especialmente por isso, os operadores, que participam da criação do Direito, ao resolverem o caso concreto, devem atuar imbuídos do espírito democrático de compreensão e convencimento, no esforço de interpretar e aplicar o Direito de forma razoável e aceitável.

O déficit de representatividade democrática dos aplicadores do Direito deve ser compensado com a prática jurídica na forma de argumentação razoável e coerente, o que exige do ensino jurídico o trabalho exaustivo com a cidadania e a responsabilidade do aluno. Este deve ser treinado como integrante da sociedade, e não como ser neutro, distante da realidade social, depurado de afetividade e sensibilidade:

[...] Quando uma opinião exerce uma influência sobre a ação, já não basta a objetividade, a menos que se entenda por isso o ponto de vista de um grupo mais amplo, que engloba ao mesmo tempo os adversários e o 'neutro'. Este é apto a julgar não como neutro - aliás, cada qual pode criticar-Ihe a neutralidade em nome de princípios comuns de justiça e direito -, mas por ser imparcial: ser imparcial não é ser objetivo, é fazer parte de um mesmo grupo que aqueles a que se julga, sem ter previamente tomado partido por nenhum deles. (OLBRECHTS-TYTECA; PERELMAN, 1996, p. 67)

O sucesso da prática jurídica como argumentação e da aplicação do método dialético depende, portanto, da inserção dos operadores na 
sociedade em que atuam. O ensino jurídico deve trabalhar a dimensão social do aluno, e não o seu alheamento. Apenas em interação com o meio no qual se vive é possível ter uma apreensão multidimensional do fato e a perspectiva da justiça, a servir de medida à aplicação da norma para a resolução do caso concreto.

\section{Conclusão: o instrumental técnico e comportamental necessário à formação do jurista em uma democracia}

Pode-se, em síntese, concluir: o ensino jurídico deve não apenas possibilitar o arsenal técnico para que o aluno possa praticar o método dialético, como treiná-lo para que ele bem vivencie a atividade de argumentação jurídica. No primeiro caso, o aluno deve ser versado não apenas nos textos normativos, mas também desenvolver conhecimentos referentes a outras ciências - Sociologia, Economia, Antropologia, Psicologia, Medicina etc. Por exemplo: o conceito jurídico de vida, que tanta repercussão traz para as leis da bioética e para a legislação penal, não pode ser traçado em desconsideração à Medicina. Da mesma forma, as definições de "mulher honesta", "injusta provocação da vítima" e "motivo fútil" exigem uma necessária incursão na realidade em que o fato é praticado.

Esses são alguns exemplos para ilustrar que o conhecimento do fato em Direito exige a sua análise multidimensional. Mas para reunir o arsenal técnico necessário à prática jurídica, o ensino do Direito deve deter-se na análise de conceitos básicos da Filosofia. Afinal, os mais relevantes conceitos filosóficos, como justiça, liberdade, igualdade e dignidade, foram positivados por Constituições democráticas, o que caracteriza uma rica interseção entre Filosofia e Direito.

Mas o ensino jurídico, além de fornecer os dados necessários, deve efetivamente vivenciá-los mediante a formação do aluno na dialética e na argumentação. Para tanto, o ensino jurídico deve empenhar-se, a fundo, em trabalhar as qualidades do compreender e convencer, dedicandose à construção de uma pré-mentalidade de cidadania democrática, participativa e integrada. 
A sala de aula e as avaliações devem ser pensadas e realizadas de forma a envolver professor e aluno em um verdadeiro diálogo jurídico, contextualizado na realidade social. A atuação do aluno passa a merecer atenção especial. O ensino, para além do respeito ao pluralismo, não pode quedar inerte em relação ao desenvolvimento dos valores basilares, necessários à prática jurídica em uma democracia, dentre os quais se destacam a sociabilidade, a responsabilidade, a tolerância e a coerência.

Ao desenvolvimento dessas conclusões, toma-se a liberdade de trazer ao presente artigo a denominação irônica que Ronald Dworkin, em seu livro O Império do Direito, atribui ao juiz que atuaria da forma que ele idealizou: juiz Hércules. É bastante provável que, neste texto, esteja-se a tratar do professor Hércules: aquele que consiga trabalhar não apenas o conhecimento normativo, mas o conhecimento totalizante, complexo e multidimensional do fato, mediante retórica caracterizada pela compreensão, coerência e convencimento. Ainda que se esteja a idealizar o professor Hércules, fica a inspiração de se buscar um modelo para sala de aula que vá além do silogismo normativo e trate de questões da atualidade, aventurando-se por uma relação dialógica integradora e crítica, em vez de funcionar como catalogação e sistematização acrítica de dados objetivos.

Ressalta-se, ainda, que as observações constantes deste trabalho não se encontram superadas pelo contexto atual, no qual a pré-mentalidade do aluno é formada pela "fundamentalização" e "judicialização" do Direito. Primeiro, porque os referidos fenômenos são aprendidos como dogmas metodológicos, obnubilando o debate sobre as competências entre Legislativo e Judiciário e sobre a relação de precedência entre princípios de justiça e democracia. Segundo, porque a "judicialização", sob o pálio dos tribunais superiores, confere à jurisprudência e às sumulas o mesmo status de supremacia que cabia à lei na era do silogismo legal. Em não raros casos, com o engessamento do Direito em moldes mais rígidos do que no Positivismo legal, uma vez que a decisão definitiva pela corte constitucional sobre princípios 
e direitos fundamentais - cláusulas pétreas - condicionaria o próprio Legislativo.

Não se está, nestas breves linhas, a criticar a judicialização e fundamentalização do Direito, mas a dogmatização metodológica da judicialização e fundamentalização do Direito, a qual suprime a instância de ponderação para além do Direito posto. Ou seja: a advertência dirige-se à conduta epistemológica consubstanciada na suficiência da Constituição positiva e da jurisprudência constitucional. É preciso, mais do que nunca, que se leve a sério as obras de Filosofia, de Filosofia Política e do Direito, bem como sobre hermenêutica jurídica, para dotar de racionalidade o diálogo jurídico.

Dito de outra forma: se a hermenêutica constitucional possibilita a adaptabilidade do Direito, ela deve, para que não se degenere em subjetivismo, resgatar as grandes questões filosóficas, epistemológicas e metodológicas. A opção para que o Direito não se transmude em mero subjetivismo, o qual se disfarça e se justifica na vaguidade dos princípios e valores fundamentais contemplados pelo texto constitucional, consubstancia-se na Filosofia, epistemologia e hermenêutica, compreendidas e apreendidas em uma prática argumentativa séria e dialógica. A abertura judicial conferida pela normatividade constitucional demanda um ensino jurídico denso, crítico e complexo, que não se limita à catalogação normativa e jurisprudencial.

As advertências feitas tornam-se mais relevantes diante da proliferação de carreiras jurídicas, que teve como consequência a inversão do foco por parte considerável do corpo discente, o qual, em vez de buscar a formação na prática jurídica caracterizada pela argumentação e dialética, tem apresentado como principal interesse a preparação para as avaliações da OAB e de concursos públicos. Como resultado, a formação do aluno tem se fixado em dados jurisprudenciais e legais que sejam úteis no bom desempenho para o ingresso em carreiras jurídicas.

A expectativa do aluno não tem diferenciado a formação em Direito do ensino de cursinhos. Nesse contexto, a fala da supremacia 
constitucional, seguida da dogmatização, fundamentalização e judicialização do Direito, tem servido de "cavalo de Troia" ao Positivismo jurisprudencial, reforçado pelo interesse do aluno na preparação para a aprovação em concurso público. No lugar de treinar argumentação coerente e aceitável, mediante o desenvolvimento de espírito crítico, grande parte dos alunos tem investido na apreensão de dados adequados ao bom desempenho em avaliações. O óbvio - a dialética -deve ser vivenciado mediante a busca do conhecimento totalizante do fato e axiológico da norma, sob argumentação coerente, razoável e integradora.

\section{Referências}

ALVES-MAZZOTTI, Alda judith; GEWANDSZNAJDER, Fernando. O método nas ciências naturais e sociais. São Paulo: Thomson Pioneira, 1998.

ALVES-MAZZOTTI, Alda judith; GEWANDSZNAJDER, Fernando. O método nas ciências naturais e sóciais: pesquisa quantitativa e qualitativa. 2. ed. São Paulo: Pioneira Thomson Learning 2002.

BECKER, Alfredo Augusto. Teoria geral do direito tributário. 3. ed. São Paulo: Lejus, 1998.

CÓSSIO, Carlos. Teoria de la verdad jurídica. Buenos Aires: Librería El Foro, 2007.

DEMO, Pedro. Metodologia do conhecimento científico. São Paulo: Atlas, 2000.

DINIZ, Márcio Augusto de Vasconcelos. Constituição e hermenêutica constitucional. 2. ed. Belo Horizonte: Mandamentos, 2002.

DWORKIN, Ronald. Justice for hedgehogs. Massachusetts: Haverd University Press, 2011. 
ENCARNAÇÃO, João Bosco da. Seis temas sobre o ensino jurídico. ENCARNAÇÃO, João Bosco; MACIEL, Getuliano do Espírito Santo (Org.). A questão do ensino jurídico. São Paulo: Cabral/Robel, 1995.

FIGUEROA, Alfonso Garcia. Princípios e positivismo jurídico. Madri: Centro de Estudos Políticos y Constitucionales, 1998.

MONTEIRO, Geraldo Tadeu Moreira. Metodologia da pesquisa jurídica: manual para elaboração e apresentação de monografias. Rio de Janeiro: Renovar, 2001.

MORAIS, José Luis Bolzan de; SANTOS, André Leonardo Copetti. 0 ensino jurídico e a formação do bacharel em direito. Porto Alegre: Livraria do Advogado, 2007.

MORIN, Edgar. Os sete saberes necessários à educação do futuro. Tradução de Catarina Eleonora F. Silva e Jeanne Sawaya. 12. ed. São Paulo: Cortez; Brasília, DF: Unesco, 2007.

PERELMAN, Chaïm. Ética e direito. Tradução Maria Ermentina Galvão. São Paulo: Martins Fonstes, 1999.

Recebido em: 00/11/13

Aprovado em: 00/12/13 